Cómo citar este trabajo: González-Romero, G., \& Caravaca-Barroso, I. (2020). Alternative economic practices in the city of Seville. Boletín de la Asociación de Geógrafos Españoles, (87). https://doi.org/10.21138/bage.2959

\title{
Prácticas económicas alternativas en la ciudad de Sevilla
}

Alternative economic practices in the city of Seville

\author{
Gema González-Romero \\ gemagonzalez@us.es \\ Inmaculada Caravaca-Barroso \\ icaravaca2@gmail.com \\ Departamento de Geografía Humana \\ Universidad de Sevilla (España)
}

\section{Resumen}

Los graves impactos provocados por la crisis sistémica y las políticas de austeridad han puesto en cuestión el modelo económico neoliberal propiciando, a su vez, el interés por prácticas económicas alternativas basadas en la colaboración ciudadana y en la solidaridad. Este artículo analiza dichas prácticas en la ciudad de Sevilla, prestando especial atención a su dimensión espacial y al papel que puedan ejercer en la evolución de ciertas zonas urbanas; se consideran, además, sus trayectorias, tipologías y actores. La ausencia de estadísticas oficiales ha requerido trabajo de campo y entrevistas. Junto a lo anterior, ha sido necesaria la aplicación de métodos y técnicas de análisis de redes sociales para poder estudiar las relaciones de colaboración inherentes a estas prácticas. De la investigación se desprende que el entorno territorial resulta clave para entender las razones que explican su proliferación y su evolución en barrios que guardan similitudes urbanísticas, socioeconómicas, culturales e ideológicas. Su destacada presencia en la zona norte del casco antiguo de la ciudad parece estar convirtiendo a algunos 
de sus barrios en espacios urbanos dinámicos, solidarios e inclusivos que pueden aportar un nuevo o renovado carácter a la ciudad.

Palabras clave: prácticas económicas alternativas; innovación social; redes de colaboración; transformaciones urbanas; Sevilla.

\begin{abstract}
The serious impacts caused by the systemic crisis and austerity policies have called into question the neoliberal economic model, which in turn fosters an interest in alternative economic practices based on citizen collaboration and solidarity. This article analyzes these practices in the city of Seville, paying special attention to their spatial dimension and the role they may play in the evolution of certain urban areas; in addition, their trajectories, typologies and actors are considered. The absence of official statistics has required fieldwork and interviews. In addition, it has been necessary to apply methods and techniques of social network analysis in order to study the relationships of collaboration inherent in these practices. The research shows that the territorial environment is key to understanding the reasons behind its proliferation and evolution in neighbourhoods that have urban, socio-economic, cultural and ideological similarities. Its outstanding presence in the northern part of the old city seems to be turning some of its neighbourhoods into dynamic, supportive and inclusive urban spaces that can bring a new or renewed character to the city.
\end{abstract}

Key words: alternative economic practices; social innovation; collaboration networks; urban transformations; Seville.

\title{
1 Introducción
}

Los graves impactos provocados por la crisis sistémica iniciada en 2008 han contribuido a poner en cuestión el modelo de funcionamiento económico que, sustentado en un creciente predomino del sector financiero, se empezó a gestar en los años setenta del pasado siglo. Favoreció la consolidación de dicho modelo el proceso de globalización neoliberal que, basado en un cuerpo doctrinal sustentado en conceptos como competitividad, talento y creación de valor, primaba los valores individuales sobre los colectivos dando cumplida respuesta a los intereses de las élites globales.

Este proceso de globalización neoliberal, además de propiciar y sustentar el modelo económico responsable de la gran recesión iniciada en 2008, inspiró las políticas de austeridad que fueron 
implementadas por la Unión Europea con el argumento de hacerle frente. Dichas políticas, no solo no contribuyeron a resolver los problemas generados por la crisis, sino que potenciaron considerablemente sus impactos, sobre todo en los países que se habían visto más gravemente afectados, provocando en ellos precariedad laboral, desempleo y crecimiento de las desigualdades socioeconómicas y territoriales. Se ponía una vez más en evidencia la creciente vulnerabilidad de un modelo de funcionamiento económico que, además de ser socialmente injusto, es ambientalmente insostenible.

Ante tal contexto, no es de extrañar que fuera creciendo un descontento social que se tradujo en la proliferación de movilizaciones ciudadanas basadas, por una parte, en acciones de protesta y resistencia y, por otra, en la generación de propuestas alternativas a este modelo económico ineficiente y falto de equidad. Dichas propuestas promueven el crecimiento de una economía más localizada, eficiente, sostenible e inclusiva que, sin someterse a la lógica del mercado ni priorizar el beneficio, pretenden resolver las necesidades materiales de las personas.

Ha crecido así el interés por la llamada economía alternativa y solidaria que, frente a las lógicas que fundamentan el capitalismo -maximización del beneficio, crecimiento económico y competitividad- promueve un modelo económico basado en la colaboración ciudadana y en la solidaridad (Askunze, 2013; Méndez, 2015; Sánchez Hernández, 2019). Adopta así formas de financiación, producción, intercambio y consumo distintas a las dominantes, que pueden considerarse socialmente innovadoras al promover el crecimiento de una economía solidaria estrechamente relacionada con el establecimiento de relaciones de cooperación que, por una parte, permiten utilizar colectivamente los recursos de proximidad y, por otra, capacitan a las sociedades para encontrar soluciones innovadoras, inclusivas y comprometidas para resolver los problemas que les afectan y adaptarse a los rápidos y profundos cambios socioeconómicos que se vienen produciendo. No hay que olvidar que la conjunción de procesos de innovación social con el buen uso de los recursos y con la conformación de redes de colaboración propicia el desarrollo territorial (Caravaca, Gónzalez-Romero \& Silva, 2005).

Tales prácticas están teniendo una significativa incidencia en los ámbitos urbanos, especialmente afectados por las crisis, al concentrarse en ellos procesos de acumulación de capital y especulación económica estrechamente vinculados a la globalización neoliberal; siendo precisamente esta lógica la que explica que en la gestión de los espacios urbanos se antepongan los intereses particulares a los generales. Ello se traduce en una concepción del suelo en la que prima su valor de cambio sobre el de uso, lo que ha contribuido a generar 
fuertes desigualdades intraurbanas. Así las cosas, es precisamente en las ciudades donde vienen surgiendo movimientos sociales asociados a nuevos entornos socioculturales en los que se funde lo público, lo compartido y lo común, propiciando la conformación de espacios de esperanza (Harvey, 2003; Muro, 2017).

En este contexto general de referencia, el objetivo de este artículo es analizar las prácticas económicas alternativas en la ciudad de Sevilla, centrando especialmente la atención en su dimensión espacial y en el papel que parecen estar ejerciendo en la evolución de ciertas zonas urbanas. Se trata, pues, de considerar las relaciones que se establecen entre dichas prácticas y el espacio urbano, lo que exige analizar sus trayectorias, actores, tipologías, localizaciones y emplazamientos, observando, a su vez, su incidencia en las transformaciones experimentadas por la ciudad. Sobre Sevilla y, a diferencia de otras grandes áreas urbanas como Madrid, Barcelona o Valencia, no existen aún estudios publicados que ofrezcan una visión de conjunto de las prácticas económicas alternativas.

La ciudad de Sevilla ocupa la cuarta posición en el sistema urbano español (INE, Padrón municipal de habitantes, 2019). Su condición de capital de Andalucía, el volumen de su población metropolitana -supera el millón y medio de habitantes-, la transformación urbanística que ha experimentado desde la última década del siglo XX y los graves efectos socioeconómicos que en ella ha tenido la crisis iniciada en 2008, la convierten en un escenario idóneo para analizar la relación entre innovación social, acción colectiva, prácticas económicas alternativas y transformaciones urbanas.

Dada la ausencia de estadísticas oficiales sobre las prácticas económicas alternativas, ha sido preciso acudir a diversas fuentes de información no siempre convencionales. A este respecto y dejando al margen las imprescindibles referencias bibliográficas, la información manejada procede de informes, páginas webs vinculadas a los distintos agentes del sector y, sobre todo, de un sistemático trabajo de campo sustentado, además, con entrevistas semiestructuradas a agentes especialmente concernidos ${ }^{1}$ (activistas directamente vinculados con estas prácticas, técnicos y representantes políticos de la administración local, e investigadores interesados por esta temática).

El artículo se divide en cinco apartados. Tras la introducción, se reflexiona en el segundo sobre la relación entre innovación social, acción colectiva, desarrollo local y prácticas económicas

1 Se han realizado siete entrevistas semiestructuradas, de más de una hora de duración. 
alternativas. El tercer epígrafe se centra en la presencia, evolución y caracterización de las prácticas económicas alternativas existentes en Sevilla. En el cuarto, se realiza una lectura territorial de dichas prácticas, considerando sus características, así como las transformaciones experimentadas por los espacios urbanos que las acogen; se presta una especial atención a la zona norte del casco antiguo de la ciudad, dado que en ella se concentra un número significativo de dichas prácticas. Se cierra el artículo con algunas consideraciones finales.

\section{Innovación social, desarrollo local y prácticas económicas alternativas}

La innovación tiene un carácter estratégico dada su capacidad para dinamizar la economía e impulsar procesos de desarrollo, pero debe concebirse desde una doble perspectiva: económica y social. Desde la perspectiva económica se asocia a las actuaciones empresariales; desde la perspectiva social está vinculada a la capacidad que muestran organizaciones, colectivos y grupos para trabajar unidos por un objetivo común; es decir, depende de la acción colectiva, cumpliendo en ella un rol decisivo la acción ciudadana. La innovación social tiene por objeto generar ideas, procesos y productos que contribuyan a mejorar las condiciones de vida del conjunto de la población, y solo existe si hay participación ciudadana y se crean redes de colaboración (Oosterlynck et al., 2013; Subirats, 2014).

La capacidad de innovar es así fundamental para las sociedades, pero también para los territorios puesto que la presencia en ellos de acciones sociales innovadoras favorece el establecimiento de relaciones de cooperación que, apostando por el bien colectivo, contribuyen a mejorar los ámbitos espaciales en los que se localizan. Dichas relaciones permiten utilizar colectivamente los recursos disponibles multiplicando con ello su eficiencia y haciendo a las sociedades más capaces de encontrar soluciones inteligentes, inclusivas y comprometidas con las que resolver los problemas que las afectan y adaptarse a los rápidos y profundos cambios que se vienen produciendo (Méndez, 2013 y 2016). La innovación social resulta, pues, decisiva para impulsar procesos de desarrollo local (Mckimon, Cumbers \& Chapman, 2002; Hillier, Moulaert \& Nussbaumer, 2004; Moulaert, Martinelli, Swyngedow \& González, 2005; Howaldt \& Schwarz, 2010).

Esta forma de innovación despierta especial interés en un periodo como el actual en el que las contradicciones de un sistema económico -basado en la obtención de lucro, sin reparar cómo éste se obtiene, y en el predominio de la cultura del capital, ligada al individualismo y a la competencia- ha contaminado a las sociedades generando en ellas una progresiva pérdida de valores éticos que deja escaso espacio a la solidaridad y a la cooperación. Como contrapunto a 
lo anterior, las capacidades de los distintos ámbitos para organizarse y para reaccionar ante circunstancias adversas están estrechamente relacionadas con la mayor o menor habilidad de sus sociedades para cooperar y trabajar por objetivos comunes (Blanco, Cruz- Gallach, Martínez \& Parés, 2016).

Teniendo en cuenta lo anterior, no puede extrañar que la innovación social esté adquiriendo un creciente protagonismo. Algunos estudiosos la relacionan sobre todo con la generación de nuevas ideas que, además de contribuir a satisfacer necesidades sociales, promueven la creación de relaciones de colaboración (Mulgan, Tucker, Ali \& Sanders, 2007; Murray, CaulierGice, \& Mulgan 2010). Otros la vinculan más a procesos de creación, implementación y difusión de prácticas sociales y económicas alternativas que, además de ser ambientalmente sostenibles, contribuyen a la inclusión social de grupos desfavorecidos (Howaldt \& Schwarz, 2010; Martínez Moreno, Cruz- Gallach, Blanco \& Salazar, 2019).

En este último sentido, es interesante la reflexión realizada por Moulaert, Martinelli, Swyngedow y González (2005) sobre lo que denominan "modelos alternativos de innovación local". Asumiendo que esta forma de innovación está ligada a la movilización ciudadana, al reforzamiento de la identidad local, y a la colaboración entre personas y organizaciones, parten de la hipótesis de que estos modelos alternativos de innovación contribuyen a propiciar el desarrollo de determinados ámbitos al generar en ellos cambios socio-institucionales que dan protagonismo a grupos sociales que tradicionalmente han estado ausentes de la política local. Se trata, pues, de una forma de innovación que promueve la cohesión y reduce la exclusión, favoreciendo la aparición de procesos de desarrollo localizados. Dichos modelos constituyen, por consiguiente, una buena herramienta para analizar cómo las organizaciones sociales y los ciudadanos logran poner en práctica ciertas estrategias y formas alternativas de funcionamiento socioeconómico que, a escala local, permiten cubrir necesidades sociales no atendidas por el mercado ni por el sector público. Se favorecen así empoderamientos comunitarios ligados a cambios que son esenciales para impulsar procesos de desarrollo socialmente inclusivos y territorialmente sostenibles (Moulaert et al., 2005; Blanco et al., 2016).

Este énfasis en los modelos alternativos de innovación local resulta especialmente interesante teniendo en cuenta que los ámbitos territoriales "capaces de vivir con menos energía, menos recursos, y menos tecnología tendrán una ventaja comparativa", y que ello está relacionado con la existencia de una "economía más local, energía más descentralizada, menos capacidad de explotación laboral, menos herramientas para el control, etc." (Fernández Durán \& González 
Reyes, 2014, p. 327). Este planteamiento es coincidente con el que hace Ollivro (2011) defendiendo la tesis de que una crisis energética de gran calado va a producir un importante encarecimiento de los costes de transportes de personas y mercancías, lo que reducirá el perímetro de vida de la gente y contribuirá a conformar un nuevo modelo económico mucho más localizado.

En un contexto como el señalado, interesa destacar aquí la importancia creciente de prácticas económicas alternativas, entendidas como

modalidades de coordinación económica (producción, distribución, consumo, financiación) cuyos participantes se rigen por principios de autonomía, reciprocidad y democracia, promueven valores no competitivos (como la solidaridad, la sostenibilidad, la cooperación, la equidad o la inclusión), operan en un ámbito local con espacios físicos de encuentro colectivo y pretenden eliminar, transformar o superar la variedad de capitalismo hegemónica en su marco geográfico de actuación (Sánchez Hernández, 2017, p 43).

Dichas prácticas pueden calificarse como innovadoras, puesto que promueven el crecimiento de una economía más localizada, eficiente, sostenible e inclusiva que, sin someterse a la lógica del mercado ni priorizar el beneficio como objetivo principal, pretenden resolver las necesidades de las personas. En la última década están alcanzando una notable relevancia social, yendo en unos casos unidas a la defensa de valores no economicistas (sostenibilidad, emancipación, anclaje territorial, solidaridad...), mientras que en otros son resultado de estrategias de adaptación a contextos de crisis y creciente exclusión social (Sánchez Hernández, 2019).

Entre tales prácticas se incluyen las vinculadas a la producción de bienes y servicios (cooperativas de trabajo asociado, redes de pequeños productores, huertos comunitarios urbanos, espacios de coworking...), el intercambio (bancos de tiempo, bancos de semillas, redes de trueque, mercados de productores, mercados de reciclaje...), el consumo (grupos y cooperativas de consumo agroecológico, cocinas compartidas, educación P2P y universidades libres...), o la financiación (moneda social, cooperativas locales de crédito...). Todas ellas se sustentan en la cooperación como forma de organización, la solidaridad como principio ético, la innovación como estrategia y la transformación social como objetivo (Méndez, 2013); en el caso que nos ocupa, se añade también como criterio selectivo la proximidad espacial. Junto a todo lo anterior, otros de los rasgos que definen a este tipo de prácticas son: carecer de una figura jurídica, operar en los márgenes de la economía formal, y sustentarse en los principios de la 
democracia deliberativa y la autogestión, tomándose las decisiones de forma asamblearia a partir del consenso (Jones \& Murphy, 2011). Los actores, promotores y protagonistas de este tipo de prácticas comparten unos mismos valores sociales e ideológicos de carácter progresista y transformador, aunque desde distintos posicionamientos frente al capitalismo (oposición, transformación o superación) (Fuller \& Jonas, 2003).

\section{Prácticas económicas alternativas en la ciudad de Sevilla}

\subsection{Origen, actores y trayectorias recientes de las prácticas económicas alternativas}

Aunque desde la década de los ochenta existen en Sevilla algunos precedentes de prácticas económicas alternativas (huertos sociales, grupos y cooperativas de consumo ecológico), su proliferación es consecuencia directa de la gran recesión iniciada en 2008 y de las políticas de austeridad impuestas después por la Unión Europea.

Al igual que ocurriera a escala nacional, tanto la crisis como las políticas de ella derivadas tuvieron efectos devastadores en la economía de la ciudad, derivando en una tasa de desempleo que pasó del 13 \% en 2008 al 31 \% en 2013 y que, en 2016, sólo había conseguido descender al $22 \%$, cifras siempre más altas que las de España: $11 \%$ en 2008, $26 \%$ en 2013 , y $20 \%$ en 2016 (INE, Encuesta de Población Activa, 2008, 2013, 2016; Ayuntamiento de Sevilla, 2019). En este contexto, no es de extrañar que hayan crecido significativamente las desigualdades, poniéndose claramente en evidencia que "la crisis económica ha revelado la realidad que se escondía debajo de la utopía neoliberal: el crecimiento exponencial de las desigualdades; el endeudamiento como instrumento de control social; y una globalización que fragmenta más que agrupa" (Ramoneda, 2014, p. 13).

El incremento del desempleo junto al deterioro del Estado del Bienestar asociado a la implementación de las políticas de austeridad, desencadenaron en Sevilla procesos de movilización colectiva que, a su vez, derivaron en respuestas ciudadanas asociadas a la búsqueda de propuestas alternativas al sistema económico o, al menos, que contribuyeran a minimizar algunos de los problemas generados por la crisis y las políticas de austeridad. La base social y los grupos promotores de muchas de estas actuaciones procedían de Ecologistas en Acción, la Red de Decrecimiento Sevilla y, en menor medida, las asambleas del $15 M^{2}{ }^{2}$ siendo

2 Como es sabido, en España durante la primavera de 2011, en un contexto de recesión económica y creciente malestar social, surgieron toda una serie de movilizaciones ciudadanas que mostraban la indignación hacia el sistema económico y los mecanismos políticos imperantes. En buena parte de los barrios de las principales ciudades se organizaron asambleas ciudadanas descentralizadas en las que se discutía sobre cómo cambiar el 
algunos de sus integrantes los que impulsaron y/o se involucraron en buena parte de las iniciativas que favorecieron la proliferación de prácticas económicas alternativas. Estos colectivos y asociaciones consideran que el modelo económico neoliberal es incompatible con la cohesión social y la sostenibilidad ambiental estando, en algunos casos, vinculados a movimientos anticapitalistas.

Teniendo en cuenta lo anterior, no se puede hacer una lectura reduccionista que identifique exclusivamente la expansión de prácticas económicas alternativas con respuestas puntuales a la crisis del capitalismo global, sino que hay que analizarlas en un contexto de reivindicación ciudadana y movilización colectiva mucho más profunda cuyo objetivo final es el de llevar a la práctica un modelo alternativo al sistema económico dominante.

Durante el periodo comprendido entre 2010 y 2014 surgieron buena parte de estas prácticas, y a partir de él se han perfilado los procesos que definen su situación en la actualidad: declive de unas frente al ascenso de otras, desarrollo de nuevos proyectos y una creciente atención a ellas por parte de las instituciones.

El menor número de iniciativas y de nuevos actores implicados en estas prácticas afecta principalmente a los bancos de tiempo, pero también a los centros sociales autogestionados. Tal y como se ha reflejado en varias de las entrevistas realizadas, son dos los motivos fundamentales que parecen dificultar la continuidad de estas iniciativas: el compromiso continuado con el proyecto y con la propia gestión de su actividad, lo que explica que sea frecuente que se generen puestos de trabajo encubiertos.

Como contrapunto a lo anterior, las actividades asociadas a redes alimentarias alternativas, como huertos urbanos y grupos de consumo agroecológicos, son las que parecen ser más dinámicas y tener una mayor continuidad; curiosamente coinciden con aquellas que se generaron antes de la crisis de 2008.

Pese a lo señalado, el dinamismo de estas iniciativas comunitarias no sólo puede medirse a partir de su propia actividad, sino que es necesario analizar también su capacidad de ramificarse y generar otros proyectos. Es el caso, por ejemplo, de la moneda social Puma cuya contribución más reciente al tejido de prácticas económicas alternativas de la ciudad de Sevilla ha sido poner

modelo económico y las formas de gobierno, proponiendo una democracia más participativa y transparente; este movimiento ciudadano fue conocido como 15M. 
en marcha un sistema de crowdfunding, Pumafunding, cuyo objetivo es financiar con microcréditos proyectos que comparten los valores que sustentan la moneda.

Hay que mencionar también que la incipiente institucionalización que vienen experimentando este tipo de iniciativas en Sevilla es un proceso que también está presente en otras ciudades españolas, como Madrid, Barcelona, Valencia, Zaragoza, Valladolid u Oviedo (Fernández \& Miró, 2016; Méndez, 2018; Sánchez Hernández, 2019; Sánchez Hernández \& Glückler, 2019). El Ayuntamiento gestiona una red de huertos urbanos que aglutina a la mayoría de los existentes y tiene además en proyecto aumentar su oferta para cubrir la demanda no cubierta de algunos barrios de la ciudad (Ayuntamiento de Sevilla, 2018). Junto a esta iniciativa, ha diseñado un proyecto de moneda social pública para el distrito Cerro-Amate, que alberga algunos de los barrios más desfavorecidos de la ciudad (C.D., 2016). Pero, sin lugar a dudas, el papel preeminente de la corporación local en el contexto de las prácticas económicas no convencionales se concreta en el banco de tiempo; en la ciudad han existido diferentes experiencias de bancos de tiempo promovidas por colectivos ciudadanos o instituciones, pero en la actualidad el único que funciona es el liderado desde el área de servicios sociales del Distrito San Pablo-Sta. Justa, dependiente del Ayuntamiento.

\subsection{Tipos de prácticas económicas alternativas}

Cuantificar el número, tipificar y ubicar las prácticas económicas alternativas presentes en la ciudad no es fácil, debido a lo mudable e inconstante de algunas y a la yuxtaposición que se produce entre ellas, hecho característico y definitorio de este tipo de actividades. De este modo, tal y como se ha revelado en las entrevistas, es habitual que coincidan los mismos actores como promotores de diferentes prácticas, tejiéndose una densa red de relaciones transversales entre unas y otras; no es extraño, además, que un mismo local sea utilizado por varias iniciativas.

En 2018, que es cuando se realiza el trabajo de campo de esta investigación, se registran veintiséis prácticas económicas alternativas; la Tabla 1 las recoge organizadas según su función dentro del circuito económico (producción, consumo, intercambios y financiación). A estas se sumarían otras siete iniciativas colectivas de carácter alternativo estrechamente relacionadas con las anteriores. 
Tabla 1. Prácticas económicas alternativas y otras iniciativas colectivas en Sevilla

\begin{tabular}{|c|c|}
\hline $\begin{array}{l}\text { FUNCIÓN DENTRO DEL } \\
\text { CIRCUITO ECONÓMICO }\end{array}$ & PRÁCTICAS ECONÓMICAS ALTERNATIVAS \\
\hline PRODUCCIÓN & 9 iniciativas \\
\hline \multirow{9}{*}{ Huertos urbanos } & Huerto Social San Jerónimo \\
\hline & Huerto del Rey Moro \\
\hline & Ecohuertos Parque Alamillo \\
\hline & Huertos de Miraflores (norte y sur) \\
\hline & Huerto Urbano Bellavista \\
\hline & Huerto Urbano IES Joaquín Romero Murube \\
\hline & $\begin{array}{l}\text { Huertos Urbanos Torreblanca (polideportivo/ Hacienda San } \\
\text { Antonio ) }\end{array}$ \\
\hline & Huertos Vecinales Parque Vega de Triana \\
\hline & Huertos Urbanos Tamarguillo (Alcosa norte y sur) \\
\hline CONSUMO & 9 iniciativas \\
\hline \multirow{9}{*}{$\begin{array}{l}\text { Grupos/Asociaciones } \\
\text { Consumo Agroecológicos }\end{array}$} & Red EcoArtesana \\
\hline & Pumarejo \\
\hline & Gazpacho Rojo \\
\hline & La Rendija \\
\hline & La Colmena Trianera \\
\hline & Casa Escuela Caracoles- La Colmena \\
\hline & Casa Cornelio \\
\hline & El Enjambre Sin Reina \\
\hline & La Ortiga \\
\hline INTERCAMBIOS & 6 iniciativas \\
\hline Bancos de Semillas & Espacio Cultivo Urbano Piperrak \\
\hline \multirow{3}{*}{$\begin{array}{l}\text { Mercado Productores } \\
\text { (agroalimentarios y artesanos) }\end{array}$} & Mercado Social Mercapuma \\
\hline & Mercadillo Agroecológico Red EcoArtesana \\
\hline & Mercado Productores Ecológicos y Locales La Alameda \\
\hline Banco de Tiempo & Banco del tiempo promovido por el Ayuntamiento \\
\hline Mercado de Trueque & Mercado Trueque La Plaza \\
\hline FINANCIACIÓN & 2 iniciativas \\
\hline Moneda social & Moneda Puma \\
\hline Crowdfunding & Pumafunding \\
\hline \multicolumn{2}{|c|}{ OTRAS INICIATIVAS Y PROYECTOS ALTERNATIVOS } \\
\hline \multirow{5}{*}{$\begin{array}{l}\text { Centros sociales/culturales } \\
\text { autogestionados }\end{array}$} & Centro Vecinal El Pumarejo \\
\hline & Centro Autogestionado La Revo (clausurado en 2018) \\
\hline & Tramallol \\
\hline & Espacio Garapa (cerrado desde 2018) \\
\hline & La Casa Ensamblá: "Despacio" Cultural \\
\hline \multirow{2}{*}{$\begin{array}{l}\text { Servicios ligados a la } \\
\text { comunicación }\end{array}$} & El Topo \\
\hline & Radiópolis \\
\hline
\end{tabular}

Fuente: elaboración propia 
Respecto a las prácticas de producción, los huertos urbanos han tenido una larga tradición en Sevilla, pero fueron desapareciendo de forma inversamente proporcional al crecimiento de la población y al proceso de expansión urbana. En la actualidad existen nueve huertos urbanos que ocupan una superficie de $274800 \mathrm{~m}^{2}$, incluyéndose entre ellos algunos de los más antiguos de España (Miraflores y S. Jerónimo) (Ayuntamiento de Sevilla, 2018). Se pueden establecer diferencias significativas entre los mismos:

- Los que se crean a partir de demanda ciudadana: Bellavista, Triana y Tamarguillo. Se inspiran en la experiencia de otros barrios, como el de Pino Montano (Huerto Miraflores).

- Los que surgen en contextos más complejos de precariedad socio-laboral: Polígono Sur y Torreblanca. En ellos el ocio queda en segundo plano, cobrando mayor importancia el autoconsumo.

- Los relacionados con colectivos activistas. La visión ecologista se plasma en el Parque San Jerónimo, promovido por Ecologistas en Acción; y el Huerto del Rey Moro que se sustenta en grupos de fuerte carácter contestatario.

- Los concebidos como equipamiento público: Ecohuertos Alamillo depende de la Agencia de Vivienda y Rehabilitación de Andalucía.

Las prácticas económicas alternativas ligadas al consumo tienen una permanencia especialmente fluctuante. Como muestra la Tabla 1, son nueve las iniciativas de este tipo, aunque hay que matizar que la Red EcoArtesana integra a varios grupos de consumo agroecológicos. No hay que olvidar, además, a grupos y asociaciones de consumo agroecológico ya desaparecidas como la Red de confianza- SAT, La Huelga, El Clarito, Crestas y lechugas...

Dentro de las actividades de intercambio se incluye toda una variedad de experiencias: bancos de semilla, mercados de productores, bancos de tiempo, mercados de trueque. Piperrak cuenta con un banco de semillas y un centro de aprendizaje sobre huerta orgánica en espacios urbanos. En los mercados de productores, agroalimentarios y/o artesanales se integran Mercapuma, vinculado a la moneda social Puma, así como los mercadillos agroecológicos de la Red EcoArtesana, y el Mercado de productores ecológicos de La Alameda. Por su parte, el único mercado de trueque con actividad es el de La Plaza. Y respecto a los bancos de tiempo, aunque en Sevilla han llegado a existir varios proyectos (Triana, Ecolocal, Puma y Universidad de Sevilla), actualmente es una práctica institucionalizada puesto que solo está funcionando el promovido por el Ayuntamiento. 
En cuanto a las prácticas de financiación, existen en Sevilla dos ejemplos intrínsecamente relacionados: la moneda social Puma y Pumafunding (Caravaca \& González-Romero, 2019). Esta moneda social nace en 2012 promovida, entre otros, por algunos de los integrantes de la Red de Decrecimiento Sevilla. Concebida a escala de barrio como moneda social tipo LETS (Local Exchange Trading Systems) ${ }^{3}$ tiene una gran importancia tanto por su trayectoria como por el número de usuarios, siendo todo un referente entre las monedas sociales existentes en España. Como extensión de sus actividades, se creó Pumafunding, una herramienta de financiación de microcréditos sin intereses dirigido a proyectos que comparten los valores fundacionales de la moneda. La propia moneda y las actividades conexas, deben contextualizarse en el proyecto de transformación social que da sentido al centro social autogestionado Casa Grande del Pumarejo. Junto al Puma, ha funcionado ocasionalmente en Sevilla otra moneda, La Oliva, en este caso en el Polígono Sur, un barrio especialmente marcado por sus circunstancias de marginalidad.

Para entender el origen y funcionamiento de las prácticas económicas alternativas es imprescindible hacer una mención especial a los centros sociales autogestionados y otros espacios culturales y de trabajo, puesto que en torno a los mismos se han gestado buena parte de las de la ciudad, por lo que funcionan como incubadoras de este tipo de iniciativas. Entre estos centros se pueden establecer diferencias en función de su carácter alternativo, contestatario y reinvindicativo, identificándose experiencias como la casa okupa autogestionada feminista La Revo, clausurada en 2018, y el centro vecinal Casa Grande del Pumarejo. Este último centro se ha convertido en un símbolo de la reivindicación ciudadana y la organización civil, no solo a escala de barrio sino de ciudad, funcionando como nodo en torno al cual se articulan espacial y organizativamente gran parte de las prácticas económicas alternativas existentes en Sevilla. Inicialmente "okupado" y después cedido por el Ayuntamiento, en él se realizan actividades diversas (biblioteca, talleres culturales, conciertos...) y es un punto de encuentro para jóvenes, estudiantes, vecinos y diversos colectivos con especial sensibilidad social y ecológica (Red Decrecimiento Sevilla, Plataforma de Afectados por la Hipoteca, Oficina de Derechos Sociales de Sevilla...).

Otro lugar de referencia urbana para las iniciativas alternativas es Tramallol, un espacio de coworking que, pese a su carácter privado, funciona como espacio público, donde además de la actividad profesional de sus integrantes, se organizan multitud de eventos. Junto al anterior, el

3 Las monedas tipo LETS están restringidas a sus usuarios y funcionan como sistemas de crédito mutuo para realizar intercambios sin ánimo de lucro. 
Espacio Garapa (cerrado en 2018), guardaba similitudes con Tramallol, pues se trataba de un espacio donde se organizaban todo tipo de talleres y eventos de carácter cultural y social; este centro fue la anterior sede de La Transicionera, una asociación cuyo objetivo era la transición hacia modelos económicos, sociales y medioambientales más justos, equitativos y sostenibles que reunía a muchos de los promotores e implicados en iniciativas vinculadas a prácticas económicas alternativas. A los anteriores centros se añade La Casa Ensamblá, una asociación sociocultural autogestionada destinada a la promoción y el intercambio cultural a través de la participación comunitaria.

También hay que hacer referencia a dos colectivos de comunicación: el Topo, un periódico que se autodefine como anticapitalista, libertario, feminista, decrecionista, ecologista y antimilitarista, que se financia a partir de suscripciones; y Radiópolis, emisora emblemática para los colectivos y movimientos ciudadanos más reivindicativos de la ciudad. Ambos, junto con los centros sociales autogestionados y otros espacios culturales y de trabajo, contribuyen a la difusión del ideario que sustenta a estas prácticas económicas alternativas, así como a su visibilidad.

Del análisis conjunto del volumen y tipologías de las prácticas económicas alternativas existentes en Sevilla se comprueba, al igual que sucede en Madrid, Valencia, Zaragoza, Alicante, Valladolid, Oviedo, Salamanca o León (Méndez \& Monteserín, 2017; Méndez, 2018; Sánchez Hernández, 2019), la preeminencia de las relacionadas con la alimentación (22 proyectos), ya sea porque se trate de bancos de semillas, huertos urbanos, grupos de consumo o mercados de productores, que dan lugar a redes que persiguen la construcción de un sistema de distribución y un orden alimentario alternativo que tiene por objeto la transformación social y ecológica (Whatmore \& Thorne, 1997; Winter, 2003; Watts, Ilbery \& Maye, 2005; Maye, Kneafsey \& Holloway, 2007).

\subsection{Articulación en red de las prácticas económicas alternativas}

Uno de los aspectos que definen el funcionamiento de las prácticas económicas alternativas es la maraña de relaciones que se establecen a nivel interno y externo, prevaleciendo las que se conforman a escala local y pueden considerarse más próximas desde el punto de vista organizativo y funcional. El conocimiento mutuo, la confianza colectiva y las identidades compartidas son aspectos claves para el nacimiento y reproducción de este tipo de prácticas (Conill, Cárdenas, Castells, Hlebik \& Servón, 2012). Como señala Méndez,

"La escala local de muchas de esas relaciones y la proximidad espacial resultan así rasgos sustantivos, que provocan concentraciones en ciertos espacios a los que dotan 
de personalidad, favoreciendo también los contactos cara a cara necesarios para animar procesos de innovación y creatividad social al posibilitar el establecimiento de vínculos de confianza y compromiso mutuo entre los participantes, generadores de capital relacional" (2018, p. 10).

Considerando la importancia que tienen las redes de colaboración en el surgimiento de prácticas económicas alternativas, se hace imprescindible incorporar en su estudio la perspectiva relacional. Desde dicha perspectiva, la estructura de las relaciones que se establecen entre los diferentes tipos de prácticas condiciona las oportunidades y limitaciones para la acción individual de cada una de ellas siendo, por tanto, de interés conocer tanto la conectividad del conjunto de la red de relaciones como la forma en que las diferentes actividades alternativas se vinculan entre sí.

Así pues, y desde el punto de vista metodológico, se ha hecho necesario recurrir al análisis de las redes sociales para comprender el funcionamiento de este tipo de iniciativas y profundizar en su conocimiento. El estudio de redes sociales puede desarrollarse a partir de la aplicación de diferentes métodos y técnicas (Wasserman \& Faust, 1994; Molina, 2001; Borgatti, Everett \& Johnson, 2013; Domínguez \& Hollstein, 2014). En este caso, la estructura de la red se ha medido considerando la densidad de los vínculos, que calcula qué proporción del número total de relaciones posibles se ha llevado a cabo de forma efectiva en la red (densidad global normalizada); por su parte, la descripción y el análisis de las posiciones de los diferentes actores se ha realizado aplicando dos medidas de centralidad: el rango y el grado de intermediación.

En el grafo que representa la estructura de la red de relaciones que sustentan las prácticas económicas alternativas, el tamaño de los nodos es proporcional a su centralidad, medida ésta a partir del número de vínculos que establecen con los otros nodos (Figura 1). La estructura de la red que subyace en Sevilla tras las iniciativas económicas alternativas y que, en buena medida, sustenta su organización y funcionamiento, viene determinada por los diez nodos que la articulan, cada uno de los cuales se corresponde con uno de los tipos de estas prácticas identificadas en Sevilla, incluyendo también los centros sociales autogestionados y los servicios colectivos de comunicación, pues, como ya se ha indicado, son fundamentales para entender la génesis, promoción y visibilidad de buena parte de las mismas. 
Figura 1. Relaciones entre prácticas económicas alternativas en Sevilla

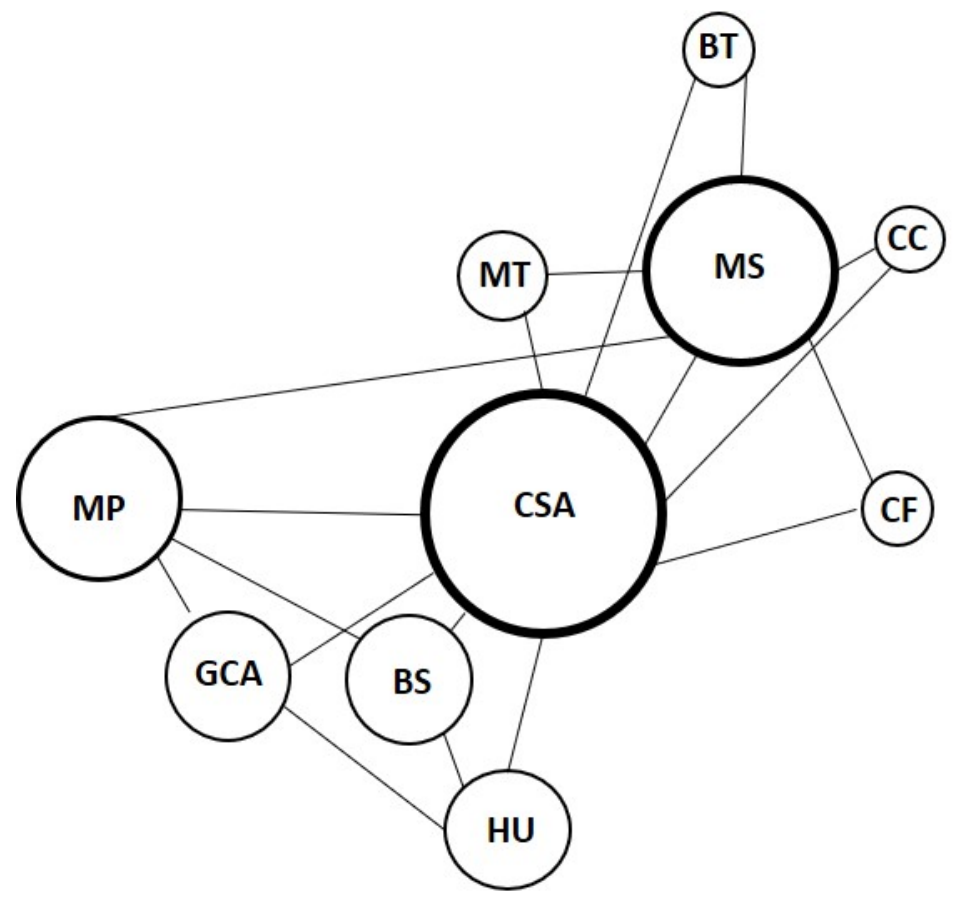

$\mathrm{HU}=$ Huertos Urbanos; GCA = Grupos Consumo Agroecológicos; BS= Bancos Semillas;

$\mathrm{MP}=$ Mercados Productores; $\mathrm{BT}=$ Banco Tiempo; $\mathrm{MT}=$ Mercado Trueque; $\mathrm{CSA}=$ Centros Sociales Autogestionados; CC= Colectivos Comunicación; MS= Moneda Social; CF= Crowdfunding.

Fuente: elaboración propia

El análisis de la estructura de la red, a partir de la medición de la densidad de las relaciones y calculada ésta en razón del número de vínculos establecidos entre los nodos respecto al total posible, evidencia que solo se alcanza el $40 \%$, lo que muestra una densidad media-baja, estando aún por desarrollar su máximo potencial relacional.

Un análisis más detallado de su funcionamiento permite entrever que dentro de la misma se conjugan diferentes subredes conformadas por prácticas que son próximas tanto desde el punto de vista organizativo como por su funcionalidad económica. Por un lado, está la subred conformada por las prácticas asociadas a la producción y distribución agroalimentaria, donde interrelacionan los huertos urbanos, banco de semillas, mercados de productores y grupos de consumo agroecológicos. Por otro, se establece una subred relativa a la distribución de productos y otros servicios donde, de nuevo, participan los mercados de productores, a los que se suman: mercado de trueque, banco del tiempo, colectivos de comunicación y moneda social. Tanto en una subred como en otra, están presentes los centros socioculturales autogestionados. 
Tan interesante como conocer la estructura de la red es el papel que cada uno de los actores desarrolla en la disposición y organización de la misma. El rango normalizado aporta información sobre qué agentes mantienen un mayor número de relaciones con otros, además de mostrar en qué medida cada uno de ellos logra explotar el potencial de relaciones que podría mantener con el resto. Los centros socioculturales autogestionados ejercen un papel capital en la conformación de la red con un rango normalizado que alcanza el $100 \%$. Junto a éstos, la moneda social cuenta también con un destacado protagonismo (67\%), así como los mercados de productores (44\%), siguiéndoles en importancia los huertos urbanos, los grupos de consumo agroecológicos y los mercados de productores (33\%); las restantes prácticas están menos interconectadas entre sí.

Respecto al grado de intermediación de los actores, tal y como refleja la figura 1, nuevamente son los centros socioculturales autogestionados quienes muestran mayor capacidad tanto para vincularse con el resto de actores, como para facilitar los contactos entre unos y otros. Ese potencial de integración que demuestran dichos centros frente a otras iniciativas económicas alternativas se explica porque, en muchos casos, físicamente dan acogida a diferentes prácticas, facilitando su conexión y porque, fundamentalmente, son lugares de encuentro, discusión y difusión del ideario de los movimientos alternativos. De esta manera, los centros socioculturales autogestionados, al funcionar como espacios de socialización, sirven a la vez de impulsores de nuevas prácticas y de puntos de enlace entre diferentes iniciativas, por lo que actúan como nodos principales de articulación de la red.

\section{Las prácticas económicas alternativas en el espacio urbano de Sevilla}

\subsection{Su localización}

En Sevilla las prácticas económicas alternativas tienen un comportamiento espacial que responde a motivaciones y contextos socioeconómicos e ideológicos que lo justifican. Tal y como se observa en la Figura 2, este tipo de prácticas se concentra mayoritariamente en la mitad norte del casco antiguo de la ciudad y más concretamente en su sector norte-noreste. 
Figura 2. Localización de las prácticas económicas alternativas en Sevilla

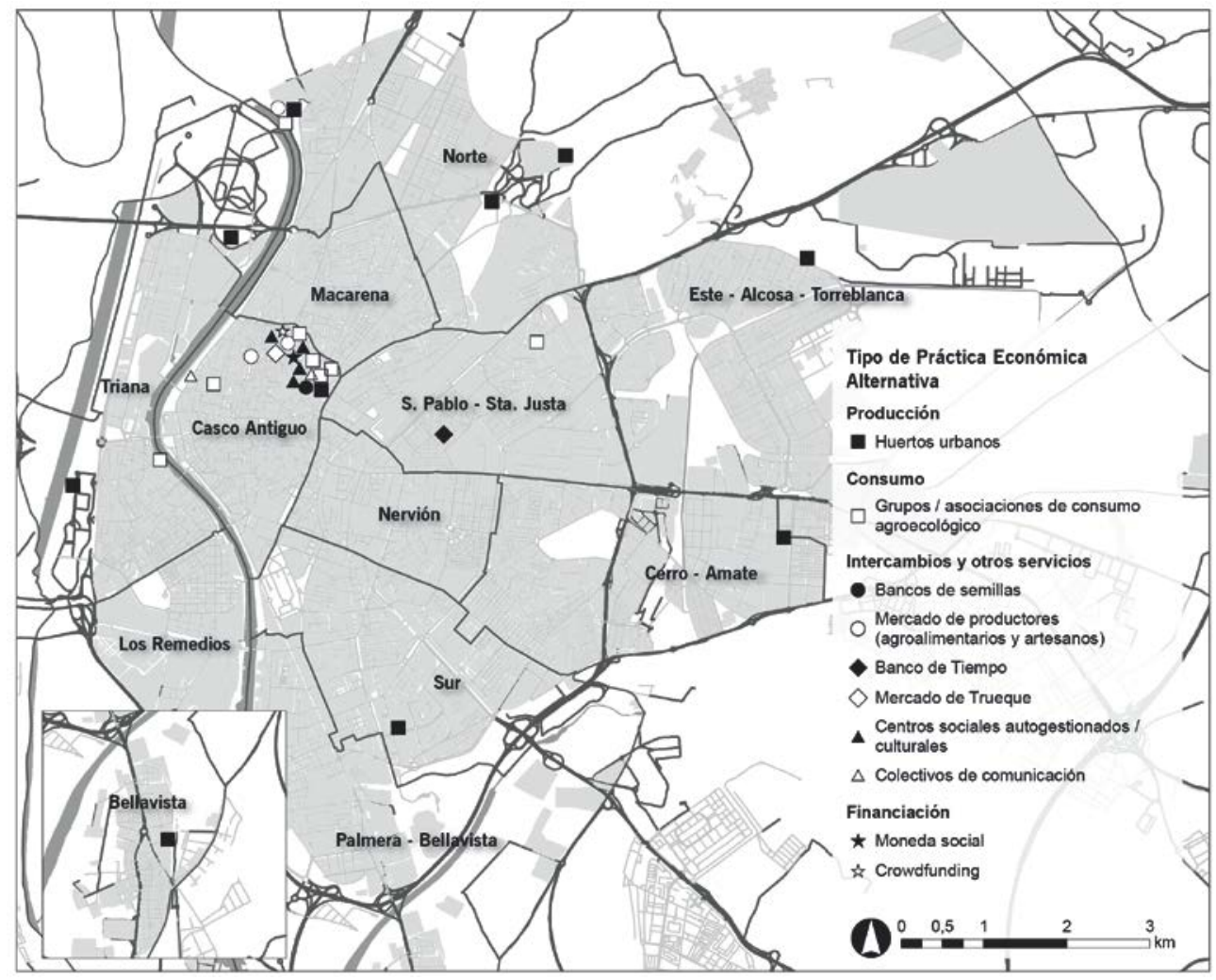

Fuente: elaboración propia

No obstante, la distribución espacial de los huertos urbanos está condicionada por la existencia de espacios libres, razón por la que su ubicación predominante es dispersa y básicamente periférica. En muchos casos, ocupan terrenos de parques públicos (Miraflores y San Jerónimo en el distrito Norte; Tamarguillo y Hacienda San Antonio en el distrito Este-Alcosa-Torreblanca; Vega de Triana en el distrito del mismo nombre); en otros, solares libres de uso dotacional de propiedad municipal (Bellavista en el distrito Palmera-Bellavista) o autonómica (Ecohuertos del Alamillo en el distrito Triana). Requiere mención aparte el Huerto del Rey Moro que, emplazado en lo que fue una huerta medieval, ocupa una parcela de unas cinco hectáreas de suelo urbano consolidado en el sector norte del distrito Casco Antiguo; se trata de un huerto social dotado de gran simbolismo, porque los movimientos ciudadanos más contestatarios lo han convertido en un espacio comunitario de resistencia y encuentro vecinal (Dimuro, 2016).

Respecto a los grupos de consumo, aun existiendo cierta dispersión de los locales y lugares donde reparten las cestas, prevalece cierta concentración. Según las entrevistas, su ubicación específica parece estar condicionada tanto por la proximidad a los consumidores, como por la disponibilidad de un local de fácil acceso y bajo precio que a menudo comparten con otras prácticas (centros autogestionados, huertos urbanos...). Siendo precisamente en la zona norte 
del Casco Antiguo donde reside un número significativo de sus usuarios y donde, a su vez, se agrupan los locales ocupados por otras prácticas alternativas, no es de extrañar que en buena parte se ubiquen en él, aunque algunos también lo hacen en barrios contiguos a esta zona.

Las actividades vinculadas al intercambio, Piperrak, Mercapuma, Mercado productores La Alameda y Mercado de trueque La Plaza, se emplazan mayoritariamente en los barrios de San Gil, San Julián y Feria (Casco Antiguo norte). También en esta zona se ubica el espacio cultural La Casa Ensamblá. Por su parte, tanto el mercadillo agroecológico de la Red EcoArtesana como el banco de tiempo del Ayuntamiento se localizan en barrios obreros del norte y noreste de la ciudad (distritos Norte, Este-Alcosa-Torreblanca y Cerro-Amate) en los que, según se señala en las entrevistas, existen problemas de integración y cohesión social entre los residentes tradicionales y los nuevos vecinos que en gran parte proceden de otros países.

En cuanto a las prácticas financieras alternativas, moneda social Puma y Pumafunding, como ya se ha comentado, están intrínsecamente relacionadas con el centro vecinal Casa Grande del Pumarejo que se ubica en la plaza del mismo nombre situada en la zona norte del Casco Antiguo. Están emplazadas también en dicha zona actividades vinculadas a la prestación de otro tipo de servicios: Centro social La Revo, Espacio Garapa, Tramallol, El Topo y Radiópolis.

\subsection{Concentración de prácticas económicas alternativas en la zona norte del Casco Antiguo}

Tal y como se viene exponiendo, las prácticas económicas alternativas existentes en la ciudad se concentran de forma significativa en la zona norte del Casco Antiguo. Tradicionalmente este sector de la ciudad se ha caracterizado tanto por su diversidad social, al tener cabida en él barrios en los que predomina la clase obrera y otros con mayor presencia de la burguesía, como por su mezcolanza de usos, al compatibilizarse el residencial con el industrial, conformado este último por talleres artesanales y algunos establecimientos fabriles (Almuedo, 1996; Caravaca, 2018).

A lo largo del siglo XX, esta zona fue experimentando un creciente proceso de deterioro que afectó a varias esferas (social, económica, urbanística...) y se hizo especialmente evidente en el entorno de la Alameda de Hércules, la Plza. del Pumarejo y el barrio de San Julián (Figura 3), ámbitos que estaban aquejados de desempleo, marginación social, deterioro de las infraestructuras básicas e insuficiencia de equipamientos dotacionales.

Estos graves problemas motivaron que entre 1994 y 1999 se implementara un Plan Urban, iniciativa de la Unión Europea cuyo objetivo era la regeneración de zonas urbanas en crisis 
mediante procesos de desarrollo innovadores e integradores que propiciaran su dinamización económica, social y cultural (Comisión Europea, 2003). Aunque la implementación de este plan supuso la renovación de infraestructuras y espacios públicos, así como la instalación de algunas nuevas dotaciones, no contribuyó a corregir los graves problemas de desempleo y marginación social. Pese a ello, la rehabilitación y regeneración urbanística de la zona derivó en un proceso de gentrificación que contribuyó a la expulsión de buena parte de las clases sociales modestas y marginales, mientras otra parte permaneció en estos barrios gracias a un importante activismo vecinal (Cantero, Escalera \& García 1999; Díaz, 2014). El proceso de gentrificación en el sector norte del distrito del Casco Antiguo se constata en aspectos sociolaborales, formativos y de renta. Así, según los datos disponibles en el último censo de población de 2011, el 61 \% de los ocupados son directivos y gerentes, técnicos y profesionales científicos e intelectuales, y otros técnicos frente al 43 \% del conjunto del municipio (INE, Censos de Población y Viviendas, 2011). En cuanto al nivel formativo, el $41 \%$ de los residentes tiene estudios de tercer grado, un porcentaje que casi duplica al $22 \%$ de conjunto de la ciudad (INE, Censos de Población y Viviendas, 2011). Por su parte, la renta media por habitante es de 14712 euros en 2017, superando en más de 3000 euros la media de la ciudad (11346 euros) (INE, Atlas de Distribución de Renta de los Hogares, 2017).

Pero, como suele ser la tónica general, los procesos de gentrificación no han sido sólo económicos sino fundamentalmente culturales, puesto que buena parte de los nuevos residentes y sujetos gentrificadores encuentran en este sector urbano ambientes alternativos y contraculturales. Teniendo en cuenta todo lo anterior, no puede extrañar que los resultados del plan hayan sido valorados de muy distintas formas prevaleciendo sobre todo la mirada crítica (Barber, Fresel \& Romero, 2006; Díaz, 2014).

Es interesante destacar que, tras el desarrollo del plan, este sector urbano ha adquirido un fuerte carácter simbólico a escala de ciudad, tanto para los colectivos que son más críticos y beligerantes con el capitalismo como para los que se limitan a buscar un ambiente socialmente dinámico, y culturalmente creativo.

Los primeros, más contestatarios al orden establecido, se han involucrado en movimientos vecinales y sociales que siguen reivindicando un cambio de sistema, pero también una mejora de las condiciones socioeconómicas y de viviendas en estos barrios, lo que tiene su mayor exponente en la casa palacio de Pumarejo situado en la plaza homónima (Figura 3). Este palacio, que había pasado a ser casa de vecinos a finales del siglo XIX, conoció en el año 2000 un 
intento de expulsión de sus residentes derivado de una operación inmobiliaria que provocó una fuerte contestación social. Más recientemente, la creciente turistización que viene experimentando este ámbito de la ciudad ha activado nuevamente el movimiento vecinal a través de diferentes colectivos: Asamblea contra la Turistización de Sevilla- CACTUS, Asociación de vecinos La Revuelta, Asociación de vecinos Casa Grande Pumarejo... (Díaz \& Jover, 2018; Jover, Berraquero-Díaz, Barrero-Rescalvo \& Jiménez-Talaver, 2018).

Junto a estos grupos críticos con el sistema, se identifican también en este sector urbano otros colectivos que persiguen un ambiente alternativo desde el punto de vista cultural e incluso laboral, aflorando nuevas profesiones vinculadas con la creatividad, así como proyectos empresariales enmarcados en el cuarto sector (García García, Fernández, Caravaca \& GonzálezRomero, 2016).

En los barrios que conforman este sector urbano, en los que tradicionalmente proliferaba la clase obrera, se está produciendo, pues, una transformación sociocultural asociada a procesos de gentrificación y turistización que contribuye a explicar el dinamismo experimentado en ellos por las prácticas económicas alternativas, en buena parte vinculadas a sectores de población con niveles formativos más altos.

Por su parte, el perfil ideológico resulta un factor influyente en la aparición de este tipo de experiencias económicas. En estos barrios, vinculados tradicionalmente a la izquierda política, se ha reforzado esta tendencia, tanto por la crisis sistémica iniciada en 2008 como por la llegada de nuevos residentes con perfiles ideológicos afines a dicha tendencia, por lo que los partidos y grupos situados más a la izquierda (Participa Sevilla, Ganemos Sevilla e Izquierda Unida-Los Verdes) concentraron en las elecciones municipales de 2015 más del $30 \%$ de los votos (INE, 2015). Tres años más tarde y esta vez en las elecciones al Parlamento de Andalucía, Adelante Andalucía (coalición formada por Podemos e Izquierda Unida) obtuvo su mayor porcentaje de votos (35\%) en los barrios de San Gil, San Julián y Feria que son los que concentran la mayor parte de prácticas económicas alternativas (Sánchez, Figueroa \& Ordaz, 2018). Resultados similares se comprueban en las elecciones municipales (30\%) y en los dos comicios a las Cortes Generales de abril (31\%) y noviembre (29\%) de 2019; en todos ellos, Unidas Podemos (coalición de Podemos, Izquierda Unida y Equo) es el partido más votado en buena parte de las secciones censales de los barrios de San Gil, San Julián y Feria (Sánchez \& Figueroa, 2019; Sánchez, Ferreiro \& Calejero, 2019; Sánchez, Figueroa, Pardo, Barrio, \& Álvarez, 2019). 
Como se comprueba en la Figura 3, la zona norte del Casco Antiguo está especialmente ligada a las prácticas económicas alternativas y en ella se pueden diferenciar tres áreas:

- Barrio de San Gil. En él está la Plaza de El Pumarejo (S.XVIII) que, como se viene diciendo, es símbolo de la lucha vecinal y la resistencia alternativa y antisistema. En esta plaza se celebra el Mercapuma, el mercado de trueque La Plaza, y se ubica el centro vecinal autogestionado Casa Grande del Pumarejo que, además de ser lugar de encuentro y de celebración de actividades promovidas por colectivos ciudadanos especialmente críticos con el orden imperante, es sede de la moneda social Puma y de Pumafunding. En sus proximidades se encontraba el Espacio Garapa, cerrado en 2018 como ya se ha indicado.

- Barrio de San Julián. En él se localizan el Huerto del Rey Moro, que más allá de su actividad agroecológica desarrolla un papel de espacio comunitario y encuentro vecinal, y Tramallol, un lugar de trabajo compartido por profesionales relacionados con el mundo de la cultura, en el que tienen cabida proyectos asociados a prácticas económicas alternativas como El Topo o Piperrak. A su vez, en la Plaza del Pelícano y su entorno se emplazan actividades como el centro social autogestionado La Revo y los proyectos de consumo alternativo El Enjambre sin Reina y La Rendija. Esta concentración en la plaza se debe a la existencia en ella de antiguos talleres y establecimientos industriales que, instalados allí tras el loteamiento de grandes parcelas procedentes de la desamortización decimonónica, conforman un paisaje industrial en el interior de algunos de los edificios que la bordean. Es interesante, además, que cohabiten en este espacio prácticas económicas alternativas con actividades creativas, favoreciendo la existencia de un espacio con "identidad propia, así como un sentimiento de pertenencia a una comunidad con señas particulares" (García García et al., 2016, p. 42).

- Barrios de Feria y San Vicente. En el primero existe un nodo central, la Alameda de Hércules (siglo XVI) que, tras su transformación en las últimas décadas, se ha convertido en un importante lugar de encuentro y sociabilidad de la ciudad. En ella se celebra el Mercado de productores ecológicos y locales La Alameda y se localiza el centro cultural La Casa Ensamblá. En el Barrio de San Vicente, por su parte, se encuentran la cooperativa de consumo ecológico La Ortiga y Radiópolis.

En resumen, en esta zona norte del Casco Antiguo de Sevilla se ha desarrollado un denso tejido de proyectos no convencionales, alternativos y creativos, con un contenido cultural e ideológico progresista y de izquierdas. Los aspectos contextuales, tales como perfil socioeconómico, cultural e ideológico, trayectoria urbana y simbolismo se revelan como factores fundamentales 
que ayudan a entender los emplazamientos de las prácticas económicas alternativas evidenciando que no responde a un patrón aleatorio.

Figura 3. Emplazamiento de las prácticas económicas alternativas en la zona norte del casco antiguo de Sevilla

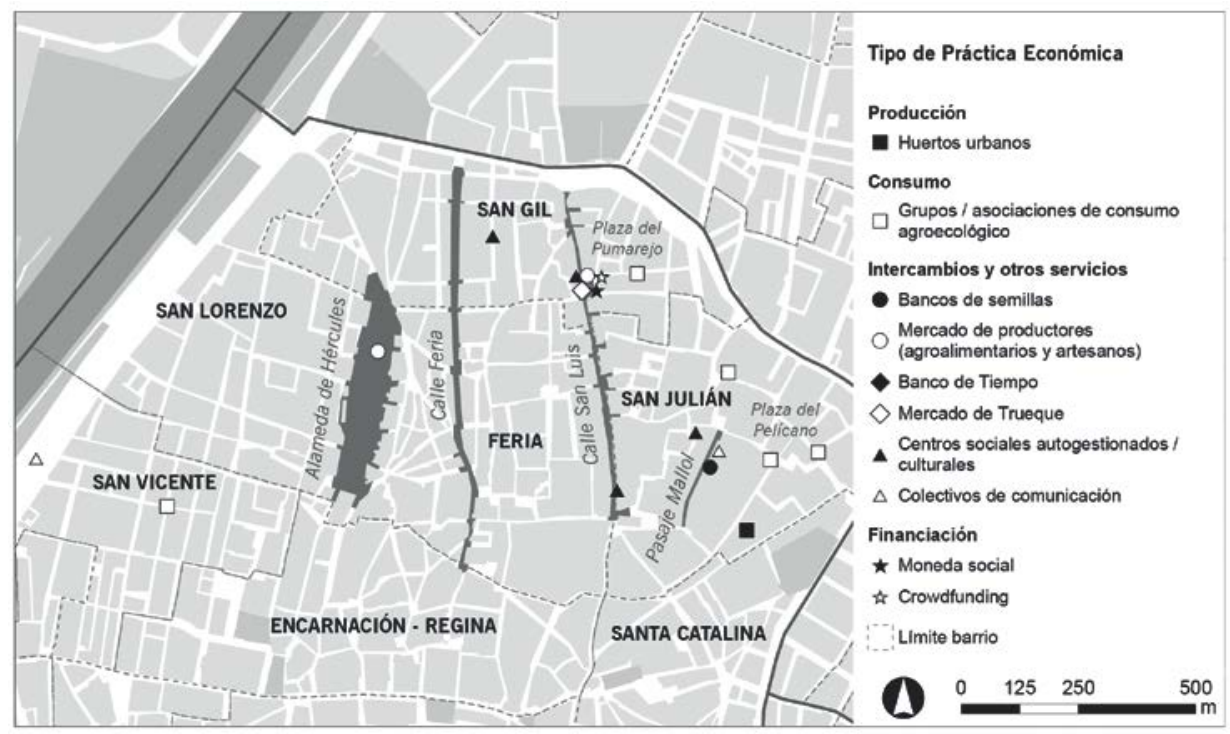

Fuente: elaboración propia

\section{Conclusiones}

Las profundas transformaciones socioeconómicas ocurridas durante la última década requieren análisis, reflexiones e interpretaciones que tengan por objeto la búsqueda de soluciones a un proceso de globalización neoliberal que, sustentado en los intereses de una minoría, no solo no está contribuyendo a resolver los problemas de la mayor parte de la población, sino que está agravándolos y provocando, además, nuevos contrastes y desigualdades que conllevan a la pérdida de cohesión social y territorial.

La situación es excepcionalmente grave por lo que, como indica Naredo (2019), es necesario cambiar la forma de entender el lucro y priorizar las necesidades de las personas para que las sociedades sean más justas y solidarias. Lamentablemente aún no se vislumbra un nuevo modelo socioeconómico que tenga como principal objetivo la búsqueda de la justicia, social y espacial (Galbraith, 1996; Soja, 2014).

En tal contexto, no es de extrañar que hayan proliferado movimientos ciudadanos de contestación al orden económico imperante que tienen un especial protagonismo en los espacios urbanos. En buena parte están ligados al crecimiento de formas alternativas de 
organización de la producción, distribución y consumo de bienes y servicios que no están basadas en la consecución de beneficios y, en consecuencia, no están sujetas a la lógica del mercado. Aunque tienen sus raíces en periodos anteriores a la crisis, ésta ha contribuido a multiplicarlas y están llegando a alcanzar una notable relevancia social, económica y mediática. Su análisis despierta, pues, un creciente interés tanto por su posible capacidad de promover procesos de desarrollo localizados, como por su potencial incidencia en la revitalización de ciertos espacios urbanos.

Teniendo en cuenta esto último, del análisis realizado pueden sacarse algunas conclusiones:

- Desde una perspectiva general, pese a que en términos económicos las prácticas económicas alternativas suelen considerarse irrelevantes, tienen cierta capacidad de generar cambios socioeconómicos muy localizados que pueden llegar a resultar significativos. Son, además, socialmente innovadoras, no sólo por sus objetivos, sino también por su origen, sus modos de organización y sus formas de funcionamiento; además de priorizar las necesidades de las personas frente al lucro, se sustentan en una base social que, organizada sobre los principios de la democracia deliberativa y la autogestión, se articula a partir de redes horizontales de cooperación y propicia formas de consumo respetuosas con el medio ambiente.

- Desde una perspectiva teórica, son varias las líneas de investigación que se ocupan de estas actividades. La literatura académica las vincula con una economía basada en la solidaridad y la justicia (Miller, 2004, 2010; Askunze, 2013; Crespo \& Sabin, 2014; Loh \& Shear, 2015; Fernández \& Miró, 2016...) que, por una parte, está relacionada con los procesos de innovación social (Hillier, Moulaert \& Nussbaumer, 2004; Moulaert et al., 2005; Mulgan et al., 2007; Murray et al., 2010; Oosterlynck et al., 2013...) y, por otra, con las redes de colaboración (Borgatti, Everett \& Johnson, 2013; Dominguez \& Hollstein, 2014; Méndez, 2015). Junto a las líneas anteriores, resulta también interesante la centrada en la búsqueda de alternativas tanto al modelo económico imperante como a la lógica del sistema capitalista (Fuller \& Jonas, 2003; Conill et al., 2012; Klein \& Roy, 2013; Muro, 2017; Sánchez Hernández, 2019).

- Desde una perspectiva metodológica, para estudiarlas hay que hacer frente a ciertos problemas entre los que cabe destacar dos. En primer lugar, dada la proliferación de categorías conceptuales utilizadas para hacer referencia a este tipo de prácticas, resulta ineludible consensuarlas para poder analizarlas con rigor. Junto a lo anterior, la falta absoluta de estadísticas oficiales que las recojan y se ocupen de recopilar información sistematizada sobre ellas dificulta significativamente su estudio y convierte en imprescindibles algunas 
fuentes de información no convencionales que, al no tener como objetivo propiciar su conocimiento, no garantizan la precisión de los datos.

- Desde una perspectiva empírica, se ha podido observar el creciente interés despertado por estas prácticas en una parte significativa de la población de Sevilla. No obstante, sus trayectorias se están viendo afectadas por tres procesos: el declive experimentado por unas frente al dinamismo observado en otras; la permanencia de algunas a lo largo del tiempo gracias a su reproducción en proyectos nuevos o renovados; y su reciente, además de creciente, institucionalización. Parece también evidente su capacidad de generar cambios socioeconómicos muy localizados que no solo se hacen notar en el tejido urbano del ámbito en que se ubican, sino que incluso pueden llegar a resultar significativos para el conjunto de la ciudad.

- Desde la perspectiva territorial, el espacio urbano de Sevilla se ha venido organizando dicotómicamente entre un sur representativo y un norte proletario, ello quizá explique al menos en parte que sea en la zona norte del Casco Antiguo donde se concentran las actividades objeto de atención. Las reformas realizadas en este último sector de la ciudad, junto a la proliferación de movimientos reivindicativos, ha configurado un complejo mosaico social que propicia el desarrollo de prácticas económicas alternativas, y que se caracteriza por una identidad propia basada en una dimensión simbólica, en una historia y cultura común, en un modo de vida propio y diferenciado, y en una ideología dominante. De la suma de iniciativas públicas, operaciones de regeneración urbana, intereses especulativos y dinámicas informales, resulta un espacio urbano de gran complejidad social que hace del Casco Antiguo norte un espacio de contrastes, muy complejo y en constante transformación.

El análisis realizado parece demostrar que el entorno urbano resulta clave para la conformación, reproducción y evolución de las prácticas económicas alternativas, aglomerándose éstas en barrios que guardan similitudes en cuanto a su caracterización socioeconómica, cultural e ideológica, trayectorias urbanas y simbolismo. Su destacada presencia en la zona norte del Casco Antiguo de Sevilla, está convirtiéndola en un espacio urbano dinámico y socialmente solidario e inclusivo, que puede aportar un nuevo o renovado carácter a la ciudad.

Para concluir y, a modo de reflexión, no puede obviarse el hecho de que este artículo se está concluyendo en el período de confinamiento decretado por el Gobierno de España como consecuencia de la pandemia motivada por la COVID-19. 
La crisis socioeconómica de 2008 fue el caldo de cultivo de buena parte de las iniciativas económicas alternativas surgidas en las ciudades españolas (Sánchez Hernández, 2019). La pandemia en la que ahora nos vemos inmersos también ha desatado una ola de solidaridad ciudadana para responder de forma urgente a las necesidades de los más vulnerables. A las crisis sanitaria y social se añade una recesión económica que se prevé alcance una magnitud hasta ahora desconocida, de la que ya se empiezan a comprobar y a temer sus consecuencias: incremento de la deuda pública, paralización de la producción y de buena parte del comercio, reducción de los flujos turísticos...

En este contexto general, se abre paso una línea de investigación sobre prácticas económicas alternativas de creciente interés. Por una parte, es necesario prestar atención al papel que pueden jugar este tipo de prácticas en la capacidad local de resistencia y resiliencia social en situaciones de crisis, observando y comparando las experiencias desarrolladas tras la crisis del 2008 y las que se produzcan con la nueva crisis que ahora se inicia. Por otra, pueden ayudar a reflexionar acerca del capitalismo neoliberal, teniendo en cuenta que no puede calificarse de democrático si no se ocupa de las necesidades de las personas.

En definitiva, son precisamente los principios que sustentan a las prácticas económicas alternativas los que pueden contribuir a propiciar un nuevo modelo económico que, atendiendo a las necesidades de las personas, sea socialmente justo, económicamente eficiente, y ambientalmente sostenible.

Agradecimientos: El artículo se encuadra en el proyecto de investigación "Espacios y prácticas económicas alternativas para la construcción de la resiliencia en las ciudades españolas" CSO2015-65452-R, que ha podido llevarse a cabo gracias a la financiación recibida de MINECO y FEDER. Asimismo, agradecemos a los revisores anónimos sus comentarios y observaciones que, sin duda, han contribuido a mejorar el artículo.

Declaración responsable: Las autoras declaran que no existe ningún conflicto de interés con relación a la publicación de este artículo. Las tareas se han distribuido de la siguiente manera: I. Caravaca ha realizado la revisión bibliográfica; G. González-Romero se ha encargado del análisis de redes sociales y ambas han participado en el trabajo de campo y la redacción del artículo. 


\section{Bibliografía}

Almuedo, J. (1996). Ciudad e industria en Sevilla. Sevilla: Diputación Provincial.

Askunze, C. (2013). Más allá del capitalismo: alternativas desde la Economía Solidaria. Documentación Social, 168, 97-2016. Retrieved from https://www.economiasolidaria.org/sites/default/files/reaslibrary/attachments/economia _solidaria_askunze.pdf

Ayuntamiento de Sevilla (2018). Red de huertos urbanos de la ciudad de Sevilla. Bases y Estrategias para la creación e integración de una Red de Huertos Urbanos en la ciudad de Sevilla. Retrieved from https://www. urbanismosevilla.org/areas/planeamiento-desa-urb/huertosurbanos-de-sevilla

Ayuntamiento de Sevilla (2019). Anuario estadístico de la ciudad de Sevilla, 2017. Retrieved from https://www.sevilla.org/servicios/servicio-de-estadistica/datosestadisticos/anuarios/2017/publicacion/anuario-estadistico-2017.pdf

Barber, S., Fresel, V., \& Romero, M. J. (Coords.) (2006). Cómo nació, creció y se resiste a ser comido. El gran pollo de la Alameda, una docena de años de lucha social en el barrio de la Alameda. Retrieved from https://www.nodo50.org/granpollodelaalameda/

Blanco, I., Cruz- Gallach, H., Martínez, R., \& Parés, M. (2016). El papel de la innovación social frente a la crisis. Ciudad y Territorio. Estudios Territoriales, 48(188), 249-260.

Borgatti, S. P., Everett, M. G., \& Johnson, J. C. (2013). Analyzing social networks. London: SAGE.

Cantero, P. A., Escalera, J., \& García, R. (1999). La ciudad silenciada: vida social y Plan Urban en los barrios del Casco Antiguo de Sevilla. Sevilla: Ayuntamiento de Sevilla.

Caravaca. I. (2018). Crisis, transformaciones urbanas e innovación social en Sevilla: contrastes y complejidades. In N. Barón \& J. Romero (Eds.), Cultura territorial e innovación social. ¿ Hacía un nuevo modelo metropolitano en el Sur de Europa? (pp. 37-50). Valencia: PUV.

Caravaca, I., González, G., \& Silva, R. (2005). Innovación, redes, recursos patrimoniales y desarrollo territorial. EURE Revista Latinoamericana de Estudios Urbano Regionales, 31(94), 524. http://dx.doi.org/10.4067/S0250-71612005009400001 
Caravaca, I., \& González-Romero, G. (2019). Una mirada alternativa al desarrollo local. Las monedas sociales en la aglomeración urbana de Sevilla. Scripta Nova. Revista Electrónica de Geografía y Ciencias Sociales, 23(621), 1- 27. https://doi.org/10.1344/sn2019.23.22487

C.D. (2016, November 30). El Consistorio estudia implantar una moneda social en Cerro Amate. Diario de Sevilla. Retrieved from https://www.diariodesevilla.es/sevilla/moneda-social-CerroAmate_0_1086192024.html

Comisión Europea (2003). Cooperación con las ciudades. La iniciativa comunitaria Urban. Retrieved from

http://ec.europa.eu/regional_policy/sources/docgener/presenta/cities/cities_es.pdf

Conill, J., Cárdenas, A., Castells, M., Hlebik, S., \& Servón, L. (2012). Otra vida es posible. Prácticas económicas alternativas durante la crisis. Barcelona: UOC Ediciones.

Crespo, B., \& Sabin, F. (2014). Los mercados sociales. La economía solidaria en acción transformadora. Documentación Social, 174, 95-116. Retrieved from https://www.economiasolidaria.org/sites/default/files/reaslibrary/attachments/Los\%20m ercados\%20sociales.pdf

Díaz, I. (2014). La gentrificación, un regreso a la ciudad de la intervención urbanística. Boletín de la Asociación de Geógrafos Españoles, 321 340. https://doi.org/10.21138/bage. 1700

Díaz, I., \& Jover, J. (2018). Enclaves urbanos de éxito. Transformación urbanística, gentrificación y turismo en la Alameda de Hércules de Sevilla. In J. Gasca Zamora (Coord.). Capital Inmobiliario y Transformaciones del Espacio Urbano Contemporáneo (pp. 337-358). México D.F.: Universidad Nacional Autónoma de México.

Dimuro, G. (2016). La producción y gestión social de la agroecología urbana en Sevilla. (Doctoral dissertation, University of Seville, Spain). Retrieved from https://idus.us.es/xmlui/handle/11441/39640

Domínguez, S., \& Hollstein, B. (Eds.). (2014). Mixed Methods Social Networks Research: Design and Applications. New York: Cambridge University Press.

Fernández Durán, R., \& González Reyes, L. (2014). En la espiral de la energía. Retrieved from https://www.ecologistasenaccion.org/29055/libro-en-la-espiral-de-la-energia/

Fernández, A., \& Miró, I. (2016). Economía social solidaria en Barcelona. Retrieved from http://www.laciutatinvisible.coop/wp-content/uploads/2016/02/essb_def3.pdf 
Fuller, D., \& Jonas, A.E.G. (2003). Alternative financial spaces. In A. Leyshon, R. Lee \& C.C. Williams (Eds.), Alternative economic spaces (pp. 55-73). London: SAGE.

Galbraith, J.K. (1996). Una sociedad mejor. Barcelona: Crítica.

García García, A., Fernández Salinas, V., Caravaca Barroso, I. \& González- Romero, G. (2016). Actividades creativas, transformaciones urbanas y paisajes emergentes. El caso del casco norte de Sevilla. Document's D'Analisi Geográfica, 62(1), 54. http://dx.doi.org/10.5565/rev/dag.245

Harvey, D. (2003). Espacios de esperanza. Madrid: Akal.

Hillier, J., Moulaert, F., \& Nussbaumer, J. (2004). Trois essais sur le rôle de l'innovation sociale dans le développement spatial. Géographie, Economie, Société, 6, 129152. https://doi.org/10.3166/ges.6.129-152

Howaldt, J., \& Schwarz, M. (2010). Social Innovation: Concepts, Research Fields and International Trends. Retrieved from

http://www.internationalmonitoring.com/fileadmin/Downloads/Trendstudien/Trendstudie_How aldt_englisch.pdf

INE (2008, 2013, 2016). Encuesta de Población Activa. Retrieved from https://www.ine.es/dyngs/INEbase/es/operacion.htm?c=Estadistica_C\&cid=125473617 6918\&menu=ultiDatos\&idp $=1254735976595$

INE (2011). Censos de Población y Viviendas. Retrieved from https://www.ine.es/dyngs/INEbase/es/operacion.htm?c=Estadistica_C\&cid=125473617 $\underline{6992 \& \text { menu }=\text { resultados\&idp }=1254735572981 \# ! \text { tabs-1254736195710 }}$

INE (2015). Base de datos de resultados electorales del Instituto Nacional de Estadística. Retrieved from

https://www.ine.es/dyngs/INEbase/es/operacion.htm?c=Estadistica_C\&cid=1254736176828 \&menu $=$ resultados\&idp $=1254735576529 \# !$ tabs-1254736195725

INE (2017). Atlas de Distribución de Renta de los Hogares. Retrieved from https://ine.es/experimental/atlas/exp_atlas_tab.htm

INE (2019). Padrón Municipal de Habitantes. Retrieved from so: https://ine.es/dyngs/INEbase/es/operacion.htm?c=Estadistica_C\&cid=1254736177012\& $\underline{\text { menu }=\text { resultados\&idp }=1254734710990 \# ! \text { tabs-1254736195461 }}$ 
Jones, A., \& Murphy, J.T. (2011). Theorizing practice in economic geography: Foundations, challenges, and possibilities. Progress in Human Geography, 35, 366392. https://doi.org/10.1177/0309132510375585

Jover, J., Berraquero-Díaz, L., Barrero-Rescalvo, M., \& Jiménez-Talaver, A., (2018). Turistización y movimientos urbanos de resistencia: experiencias desde Sevilla. In C. Milano \& J. A. Mansilla (Coords.), Ciudad de vacaciones. Conflictos urbanos en espacios turísticos (pp. 403-437). Barcelona: Pol-hen Edicions.

Klein, J.L., \& Roy, M. (2013). Pour une nouvelle mondialisation. Le défi d'innover. Quebec: Presses de I'Université du Québec.

Loh, P., \& Shear, B. (2015). Solidarity economy and community development: emerging cases in three Massachusetts cities. Community Development, 46, 244260. https://doi.org/10.1080/15575330.2015.1021362

Martínez Moreno, R., Cruz- Gallach, H., Blanco, I., \& Salazar, Y. (2019). La innovación social, ¿prácticas para producir autonomía, emprendimiento y nueva institucionalidad? Revista Internacional de Sociología, 77(2). https://doi.org/10.3989/ris.2019.77.2.022

Maye, D., Kneafsey, M. \& Holloway, L. (2007). Introducing alternative food geographies. In D. Maye, L. Holloway \& M. Kneafsey eds. Alternative food geographies. Representation and practice (pp. 1-20). Amsterdam: Elsevier.

Mckimon, D., Cumbers, A., \& Chapman, D. (2002). Learning, innovation and regional development: a critical appraisal of recent debates. Progress in Human Geography, 26, 293311. https://doi.org/10.1191/0309132502ph371ra

Méndez, R. (2013). Estrategias de innovación para el desarrollo y la resiliencia de ciudades medias.

Documents

d'Anàlisi

Geogràfica, 59(3), $481-$ 499. https://doi.org/10.5565/rev/dag.60

Méndez, R. (2015). Redes de colaboración y economía alternativa para la resiliencia urbana: una agenda de investigación. Biblio3w, 20(1139). Retrieved from http://www.ub.es/geocrit/b3w1139.pdf

Méndez, R. (2016). Renovar economias urbanas en crisis: Un debate actual sobre la innovación. Desenvolvimento Regional em debate, 6(3), 4-31. Retrieved from https://dialnet.unirioja.es/servlet/articulo?codigo=5733101

Méndez, R. (2018). Redes económicas alternativas ¿ para una sociedad postcapitalista? Algunas 
experiencias en Madrid. In Las ciencias sociales y la edificación de una sociedad post-capitalista (pp. 1-22). Actas del XV Coloquio Internacional de Geocrítica. Barcelona, May, 7-12. Retrieved from http://www.ub.edu/geocrit/XV-Coloquio/RicardoMendez.pdf

Méndez, R., \& Monteserín, O. (2017). Redes alimentarias alternativas en grandes ciudades: los mercados de productores agrarios en Madrid. Cuadernos Geográficos, 56(1), 193-216. Retrieved from https://dialnet.unirioja.es/servlet/articulo?codigo=5960914

Miller, E. (2004). Solidarity economics. Strategies for building new economies from the bottomup and the inside-out. Retrieved from http://ussen.electricembers.net/files/SolidarityEconomicsEthanMiller.pdf

Miller, E. (2010). Solidarity economy: key concepts and issues. In E. Kawano, T. Masterson \& J. Teller-Ellsberg (Eds.), Solidarity Economy l: Building alternatives for people and planet (pp. 25-41). Amherst, M.A.: Center for Population Economics.

Molina, J.L. (2001). El análisis de redes sociales. Una introducción. Barcelona: Edicions Bellaterra. Moulaert, F., Martinelli, F., Swyngedow, E., \& González, S. (2005). Towards alternative model(s) of local innovation. Urban Studies, 19691990. https://doi.org/10.1080/00420980500279893

Mulgan, G., Tucker, S., Ali, R., \& Sanders, B. (2007). Social Innovation. What it is, why it matters and how it can be accelerated. Oxford: Said Business School. Retrieved from http://youngfoundation.org/publications/social-innovation-what-it-is-why-it-matters-how-itcan-be-accelerated/

Muro, I. (2017, Jun 29). El agotamiento de la ciudad neoliberal. Economistas frente a la crisis, 29 junio [Blog]. Retrieved from https://economistasfrentealacrisis.com/el-agotamiento-de-la-ciudadneoliberal/

Murray, R, Caulier-Gice, J., \& Mulgan, G. (2010). The open book of social innovation. Retrieved from http://youngfoundation.org/wp-content/uploads/2012/10/The-Open-Book-of-SocialInnovationg.pdf.

Naredo, J.M. (2019). Taxonomía del lucro. Madrid: Ed. Siglo XXI.

Ollivro, J. (2011). La Nouvelle économie des territoires. Rennes: Editions Apogée.

Oosterlynck, S., Kazepov, Y., Novy, A., Cools, P., Barberis, E., Wukovitsh, F., \& Saruis, T. (2013). The butterfly and the elephant: Local social innovation, the welfare state and new poverty 
dynamics. Improve Discussion Paper, 13(3), 119-139. Retrieved from http://improve-research.eu Ramoneda, J. (2014, November 9). El 9-N genuino. El País. Retrieved from http://elpais.com/elpais/2014/11/07/opinion/1415357716_485519.html

Sánchez, R. Figueroa, H., \& Ordaz, A. (2018, December 3). MAPA. ¿Qué votaron tus vecinos en las elecciones andaluzas? Los resultados electorales, calle a calle. Eldiario.es. Retrieved from hittps://www.eldiario.es/andalucia/MAPA-partido-elecciones-andaluzasmanzana_0_842366730.html

Sánchez, R., \& Figueroa, H. (2019, May 2). ¿Qué votaron tus vecinos en las elecciones generales? Los resultados del 28A por partido y por bloque izquierda-derecha, calle a calle. Eldiario.es. Retrieved from https://www.eldiario.es/politica/votaron-elecciones-generalesresultados-calle_0_894860668.html

Sánchez, R., Ferreiro, D.F., \& Calejero, A. (2019, May 29). ¿Qué votaron tus vecinos el 26M? Los resultados de las elecciones generales, calle a calle. Eldiario.es. Retrieved from https://www.eldiario.es/politica/votaron-elecciones-municipales-resultadoscalle_0_904309592.html

Sánchez, R. Figueroa, H., Pardo, A., Barrio, F., \& Álvarez, P.J. (2019, November 11). ¿Qué votaron tus vecinos el 10N? Los resultados de las elecciones generales, calle a calle [Map]. Eldiario.es (Andalucía). Retrieved from https://www.eldiario.es/politica/votaron-resultadoselecciones-generales-calle_0_962404599.html

Sánchez Hernández, J.L. (2017). Las prácticas económicas alternativas en perspectiva geográfica. Salamanca: Universidad de Salamanca. Retrieved from https://saladeprensa.usal.es/filessp/Las_pr_cticas_econ_micas.pdf

Sánchez Hernández, J.L. (Coord.) (2019). Espacios y prácticas económicas alternativas en las ciudades españolas. Cizur Menor (Navarra): Thomson Reuters Aranzadi.

Sánchez Hernández, J.L., \& Glückler, J. (2019). Alternative economic practices in Spanish cities: from grassroots movements to urban policies? An institutional perspective, European Planning Studies, 27, 2450-2468. https://doi.org/10.1080/09654313.2019.1644295

Soja, E.W. (2014): En busca de la justicia espacial. Valencia: Tirant Humanidades.

Subirats, J., (2014): Si la innovación social es la respuesta. ¿Cuál era la pregunta? Los debates en torno a la sostenibilidad de las políticas de bienestar. Papeles de Relaciones Económicas y Cambio Global, 126, 49-56. Retrieved from https://www.fuhem.es/papeles_articulo/si-la- 
innovacion-social-es-la-respuesta-cual-era-la-pregunta-los-debates-en-torno-a-la-sostenibilidad-de-laspoliticas-de-bienestar/

Wasserman, S., \& Faust, K. (1994). Social Network Analysis. Methods and Applications. Cambridge: Cambridge University Press.

Watts, D., Ilbery, B., \& Maye, D. (2005). Making reconnections in agro-food geography: alternative systems of food provision. Progress in Human Geography, 29, 22 40. https://doi.org/10.1191/0309132505ph526oa

Whatmore, S,. \& Thorne, L. (1997). Nourishing networks: alternative geographies of food. In D. Goodman \& M. J. Watts (Eds.), Globalising food. Agrarian questions and global restructuring (pp. 287-304). London: Routledge.

Winter, M. (2003). Geographies of food: agro-food geographies - making reconnections. Progress in Human Geography, 27, 505-513. https://doi.org/10.1191/0309132503ph446pr 